\begin{tabular}{c} 
Brazilian Journal \\
of Chemical \\
Engineering \\
\hline
\end{tabular}

ISSN 0104-6632 Printed in Brazil www.abeq.org.br/bjche

Vol. 28, No. 03, pp. 495 - 504, July - September, 2011

\title{
EFFECT OF K PROMOTER ON THE STRUCTURE AND CATALYTIC BEHAVIOR OF SUPPORTED IRON-BASED CATALYSTS IN FISCHER-TROPSCH SYNTHESIS
}

\author{
F. E. M. Farias ${ }^{1}$, R. C. Rabelo Neto ${ }^{2}$, M. A. S. Baldanza ${ }^{2}$, M. Schmal ${ }^{2}$ and F. A. N. Fernandes ${ }^{1 *}$ \\ ${ }^{1}$ Universidade Federal do Ceará, Departamento de Engenharia Química, Phone: + (55) (85) 3366-9611, \\ Fax: + (55) (85) 3366-9610, Campus do Pici, Bloco 709, 60455-760 Fortaleza - CE, Brasil. \\ E-mail: fabiano@ufc.br \\ ${ }^{2}$ Universidade Federal do Rio de Janeiro, NUCAT/PEQ/COPPE, Centro de Tecnologia, Bloco G, Sala G-128, \\ Cx.P. 68502, CEP: 21945-970, Rio de Janeiro - RJ, Brasil.
}

(Submitted: August 8, 2010 ; Revised: April 5, 2011 ; Accepted: April 26, 2011)

\begin{abstract}
Effects of K addition on the performance of supported Fe catalysts for Fischer-Tropsch synthesis (FTS) were studied in a slurry reactor at 240 to $270^{\circ} \mathrm{C}, 2.0$ to $4.0 \mathrm{MPa}$ and syngas $\mathrm{H}_{2} / \mathrm{CO}=1.0$. The catalysts were characterized by $\mathrm{N}_{2}$ adsorption, $\mathrm{H}_{2}$ temperature programmed reduction, X-ray diffraction, X-ray fluorescence, thermogravimetric analysis, scanning electron microscopy and dispersive X-ray spectroscopy. A strong interaction was observed between Fe and K, which inhibited the reduction of Fe catalyst. Addition of potassium increased the production of heavy hydrocarbons (C20+).

Keywords: Fischer-Tropsch synthesis; Hydrocarbons; Iron catalyst; Slurry reactor.
\end{abstract}

\section{INTRODUCTION}

The Fischer-Tropsch synthesis (FTS) is considered to be an efficient route to convert syngas $\left(\mathrm{CO}+\mathrm{H}_{2}\right.$ mixture) into a mixture of linear and branched hydrocarbons. Carbon monoxide and hydrogen react to form, in situ, a methylene radical $\left(-\mathrm{CH}_{2}-\right)$ that polymerizes, producing short and long chain hydrocarbons.

The synthesis is usually carried out using iron or cobalt catalysts. Iron-based catalysts are able to generate more long chain hydrocarbons (diesel and waxes cut), produce less methane and are less sensitive to poisoning (Bartholomew and Bowman, 1985). Iron-based FTS catalysts are also preferred when coal or biomass derived synthesis gas are used because of their high activity in the water gas shift (WGS) reaction. The high activity in the WGS reaction allows the use of synthesis gas with low $\mathrm{H}_{2} / \mathrm{CO}$ ratios (lower than 1.0) without needing to employ an upstream WGS unit (Davis, 2007).

Pure iron oxide catalysts provide low syngas conversion and high amounts of light hydrocarbons (C1 to C5). The use of promoters in iron-based catalysts enhances both selectivity and activity of the catalyst. Attempts to enhance fuel selectivity were studied by adding chemical and structural promoters, such as K (Miller and Moskovits, 1988; Yang et al., 2004; Farias et al., 2008), Cu (Bukur et al., 1990), Mn (Maiti et al., 1983, 1985; Bai et al., 2002; Li et al., 2007; Lohitharn and Goodwin Jr., 2008), Mo (Dun et al., 2985; Qin et al., 2009), Mg (Tao et al., 2007; Pour et al., 2010), La (Pour et al., 2010), Ca (Pour et al., 2010) and zeolite (Botes and Böhringer, 2004; Martínez and López, 2005), into iron-based catalysts.

*To whom correspondence should be addressed 
Potassium suppresses the production of methane and improves the effective hydrocarbon selectivity (Miller and Moskovits, 1988; Yang et al., 2004). The effect of potassium has been mostly studied in precipitated iron-based catalysts and fewer studies have reported its influence in supported iron-based catalysts.

This work reports the effects of potassium on the catalytic behavior of a supported iron-based catalyst. The characterization of the catalyst and the results of the reactions carried out at high pressure (20 to $30 \mathrm{~atm}$ ) in a slurry phase reactor are presented and discussed.

\section{EXPERIMENTAL}

\section{Catalyst Preparation}

The iron-based catalyst precursors were prepared by impregnation of an aqueous $\mathrm{Fe}\left(\mathrm{NO}_{3}\right) \cdot 9 \mathrm{H}_{2} \mathrm{O}$ solution in the support $\left(\mathrm{SiO}_{2}\right)$. After impregnation of $\mathrm{Fe}$, the desired amount of $\mathrm{K}$ was added by aqueous impregnation with $\mathrm{K}_{2} \mathrm{CO}_{3}$, followed by aqueous impregnation with $\mathrm{CuNO}_{3}$. The precursors were calcined at $350^{\circ} \mathrm{C}$ for $5 \mathrm{~h}$ to obtain the final catalysts.

Three levels of potassium loading in the catalyst were studied and the compositions of the final catalysts were $100 \mathrm{Fe} / 5 \mathrm{Cu} / 6 \mathrm{~K} / 139 \mathrm{SiO}_{2}, 100 \mathrm{Fe} / 5 \mathrm{Cu} / 12 \mathrm{~K} / 139 \mathrm{SiO}_{2}$ and $100 \mathrm{Fe} / 5 \mathrm{Cu} / 18 \mathrm{~K} / 139 \mathrm{SiO}_{2}$ on a molar basis, and were denoted respectively as $6 \mathrm{KFe}, 12 \mathrm{KFe}$ and $18 \mathrm{KFe}$.

Copper was added to the catalyst because the copper-promoted catalyst has more active sites than the copper-free catalyst. The effect of adding copper to silica-containing precipitated iron catalysts is mainly an increase in the rate of reduction of iron, leading to a larger number of active sites (Hayakawa et al., 2006). The amount of copper used in the catalyst was based on literature information regarding the optimal amount of copper in iron-based catalysts (Bukur and Sivaraj, 2002; Hayakawa et al., 2006).

The catalyst was crushed and sieved to obtain particles with diameters in the range of $50-150 \mu \mathrm{m}$, which is a particle size for which it is safe to neglect intraparticle transfer limitations and easy to use in the reactor during the experiment (Pour et al., 2010).

\section{Catalyst Characterization}

The BET surface area, pore volume and average pore diameter of the fresh catalysts were obtained by nitrogen physisorption at $-196^{\circ} \mathrm{C}$ in a Quantachrome model Autosorb-1MP. Each sample was degassed under vacuum at $90^{\circ} \mathrm{C}$ for $1 \mathrm{~h}$ and $200^{\circ} \mathrm{C}$ for $12 \mathrm{~h}$ prior to the measurement.
The solids were characterized by chemical analysis (X-ray fluorescence, Rigaku model RIX-3100 instrument). Powder X-ray diffraction (XRD) patterns were obtained with a D/max-RA X-ray diffratometer (Rigaku, Japan), equipped with $\mathrm{Cu} \mathrm{K \alpha}$ radiation $(\lambda=1.5406 \AA)$ at $40 \mathrm{kV}$ and $150 \mathrm{~mA}$.

Reduction behavior was measured by temperature programmed reduction experiments (TPR) with an Autochem II 2920 equipment (Micromeritics, USA). A sample of $40 \mathrm{mg}$ of catalyst was loaded into a U-type quartz tube reactor and heated from room temperature to $1000^{\circ} \mathrm{C}$ in $10 \% \mathrm{H}_{2} / 90 \% \mathrm{Ar}\left(\mathrm{H}_{2}\right.$-TPR). The heating rate was maintained at $6^{\circ} \mathrm{C} / \mathrm{min}$ and the flow rate at $50 \mathrm{~mL} / \mathrm{min}$. The variation of the reducing gas concentration was monitored with a thermal conductivity detector (TCD). Isopropyl alcohol gel $\left(-88^{\circ} \mathrm{C}\right)$ and a liquid nitrogen trap were used to remove water (in $\mathrm{H}_{2}$-TPR) formed during the tests.

The thermogravimetric analysis (TGA) was performed using a Metler model TGA/SDTA 851 instrument. Samples of $20 \mathrm{mg}$ were treated in $50 \% \mathrm{H}_{2}$ (on a mol\% basis) mixed with $\mathrm{Ar}$ at ambient conditions for $10 \mathrm{~min}$ and then the temperature was increased from room temperature to $1073 \mathrm{~K}$ at a rate of $10 \mathrm{~K} / \mathrm{min}$ and held for $5 \mathrm{~min}$ before cooling.

The catalyst morphologies were studied by using scanning electron microscopy (SEM). The elemental distributions on the surface of the catalyst particles were determined using dispersive X-ray spectroscopy (EDXS). SEM was performed using a Hitachi FESEM-S4800 in the scanning electron (SE) mode. The accelerating voltage was $20 \mathrm{kV}$, with a working distance of $15 \mathrm{~mm}$.

Elemental analysis was carried out to determine the surface composition and distribution of each element on the cross-sectional surface of the catalyst particles using an Oxford INCA 300 energy dispersive X-ray spectroscope. Cross-sections of the catalyst particles were prepared by mixing the particles with low-viscosity polymer gel; after consolidation of the polymer gel, particles were cut using a microtome. The microtome samples were mounted and the resulting flat surface was used for EDXS. The polished surface was coated with gold/palladium for $80 \mathrm{~s}$ in $20 \mathrm{~s}$ intervals.

\section{Catalyst Evaluation}

FTS testing was conducted in a $1 \mathrm{~L}$ continuous stirred tank reactor loaded with $10 \mathrm{~g}$ of catalyst sample and $300 \mathrm{~g}$ of paraffin (C26 30\%, C27 40\%, C28 30\% molar basis). The flow rates of the gases $\left(\mathrm{CO}\right.$ and $\left.\mathrm{H}_{2}\right)$ were controlled separately by mass flow meters 
(Aalborg GFC, USA). The vapor phase in the region above the slurry passed continuously to the warm $\left(80^{\circ} \mathrm{C}\right)$ and the cold $\left(0^{\circ} \mathrm{C}\right)$ traps located outside the reactor. The light wax and water mixture was collected from the warm trap and an oil plus water sample from the cold trap. The tail gas was analyzed by gas chromatography (GC) (Thermos Ultra, USA). The liquid sample was withdrawn after $12 \mathrm{~h}$ and analyzed by gas chromatography (Thermos Ultra, USA).

$\mathrm{CO}$ and $\mathrm{H}_{2}$ mass flow controllers were used to provide a simulated synthesis gas of the desired composition. Syngas was introduced at a rate of $10 \mathrm{~L}(\mathrm{NTP}) \cdot \mathrm{h}^{-1} \cdot \mathrm{g}_{\mathrm{Fe}^{-1}}$. Reaction conditions were 240-270 ${ }^{\circ} \mathrm{C}, 2.0-3.0 \mathrm{MPa}, \mathrm{H}_{2} / \mathrm{CO}=1.0$, and a stirrer speed of $800 \mathrm{rpm}$. Prior to the FTS assays, calcined catalysts were loaded into the reactor and activated in situ with pure $\mathrm{CO}$ at $280^{\circ} \mathrm{C}$ and $0.8 \mathrm{MPa}$ for $8 \mathrm{~h}$.

\section{RESULTS AND DISCUSSION}

\section{Molar Composition and Crystallite Structure of the Catalysts}

Table 1 contains characterization data for the various catalysts promoted with $\mathrm{K}$ and $\mathrm{Cu}$. The promoter loadings were very close to the predicted values, indicating the efficiency of the incipient wetness method for catalyst production.

The XRD patterns of the fresh catalysts are presented in Figure 1. All the XRD patterns show broad diffractograms with several diffraction peaks at $2 \theta$ values of $24^{\circ}, 33^{\circ}, 36^{\circ}, 41^{\circ}, 50^{\circ}, 54^{\circ}, 62^{\circ}$ and $63^{\circ}$, all of which are characteristic of hematite $\left(\alpha-\mathrm{Fe}_{2} \mathrm{O}_{3}\right)$, according to the JCPDS database. The diffraction intensity of hematite increased with increasing potassium content. The peaks at 50 and $54^{\circ}$ were evident as the amount of potassium in the catalyst increased. Increase in these peaks was also reported by Wu et al. (2004).

The peak at $41^{\circ}$ corresponds to the iron carbide phase, which was more evident as the amount of potassium in the catalyst increased. The $6 \mathrm{KFe}$ catalyst did not present significant intensity at $41^{\circ}$. The XRD patterns show the existence of iron carbides in the catalysts after reaction, whereas it is difficult to distinguish the type of iron carbide due to the weak diffraction signal. These results indicate that potassium as promoter can facilitate the formation of iron carbide in the FTS reaction (Jin and Datye, 2000).

No evidence was found that $\mathrm{Cu}$ was in the form of $\mathrm{CuO}$, which would be indicated by its characteristic peaks at $2 \theta=35.5^{\circ}$ and $39^{\circ}$.

Table 1: Characterization data for the catalysts

\begin{tabular}{|c|c|c|c|c|}
\hline Catalyst & \multicolumn{4}{|c|}{ Molar Composition } \\
\hline & $\mathbf{F e}$ & $\mathbf{K}$ & $\mathbf{C u}$ & $\mathrm{SiO}_{2}$ \\
\hline $6 \mathrm{KFe}$ & 100 & 6.4 & 3.6 & 155.2 \\
\hline $12 \mathrm{KFe}$ & 100 & 12.9 & 3.8 & 163.5 \\
\hline $18 \mathrm{KFe}$ & 100 & 18.1 & 4.3 & 139.9 \\
\hline & \multicolumn{4}{|c|}{ Mass Composition } \\
\hline & $\mathbf{F e}$ & $\mathbf{K}$ & $\mathbf{C u}$ & $\mathrm{SiO}_{2}$ \\
\hline $6 \mathrm{KFe}$ & 100 & 2.2 & 1.9 & 129.8 \\
\hline $12 \mathrm{KFe}$ & 100 & 4.5 & 2.0 & 136.7 \\
\hline $18 \mathrm{KFe}$ & 100 & 6.3 & 2.3 & 117.0 \\
\hline
\end{tabular}

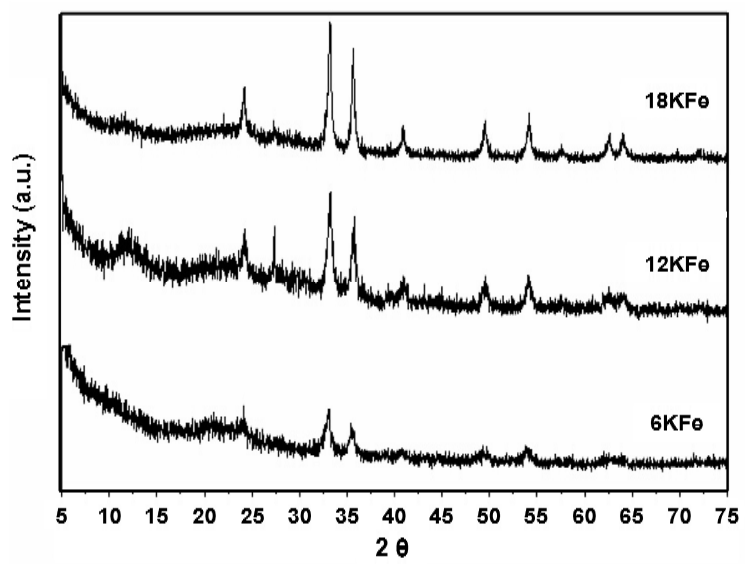

Figure 1: XRD patterns of the fresh catalysts with different potassium levels. 


\section{Surface Properties of the Catalysts}

The BET surface area, pore volume and average pore diameter of the catalysts are illustrated in Table 2 .

It is evident that $\mathrm{K}$ addition results in a decrease in both the BET surface area and the total pore volume of the $\mathrm{Fe}$ catalyst. The average pore diameter of all studied $\mathrm{KFe}$ catalysts did not change with increasing $\mathrm{K}$ addition. The decrease in the BET surface area as the potassium content in the catalyst increased may be caused by the formation of larger hematite crystallites that are promoted by potassium, which was also evidenced by the SEM studies in the present study. Pore blocking by alkaline molecules may not be contributing to the decrease in BET surface area (Jin and Datye, 2000). Dry and Oosthuizen (1968) suggested that strong bases like K can decrease the surface area of the Fe catalyst by increasing the $\mathrm{Fe}$ crystallite size.

Compared with the $\mathrm{Fe}$ catalyst, $\mathrm{Fe} / \mathrm{Cu}$ catalysts (with no $\mathrm{K}$ addition) have larger surface area and pore volume and smaller pore size (Wan et al, 2008). The addition of $\mathrm{Cu}$ promoter facilitates high dispersion of the catalyst metals. The large surface area of the $\mathrm{Fe} / \mathrm{Cu}$ catalyst can be attributed to the small catalyst crystallites. The addition of $\mathrm{K}$ promoter decreases the BET surface area and pore volume of $\mathrm{Fe} / \mathrm{Cu} / \mathrm{K}$ catalysts compared to $\mathrm{Fe}$ or $\mathrm{Fe} / \mathrm{Cu}$ catalysts; thus, the effect reported in Table 2 is due to the addition of potassium and not to the presence of copper in the catalyst.

The results obtained by Dry and Oosthuizen (1968) for a fused iron catalyst indicated that an increase in the alkali content of the catalyst resulted in a loss of surface area. Similar result was observed by Bukur and Sivaraj (2002), who reported BET surface areas near the ones reported herein. Lohitharn and Goodwin (2008) observed a decrease in the surface area of $\mathrm{Fe}$ and $\mathrm{Fe} / \mathrm{Mn}$ catalysts with an increase in potassium content. Lohitharn and Goodwin (2008) reported that the surface area of $\mathrm{Fe} / \mathrm{K}$ catalysts increased upon incorporation of $\mathrm{Mn}$ in the catalyst.

Table 2 also shows the BET results for a precipitated iron-based catalyst. The use of a silica support increases greatly the BET surface area of the catalyst.

\section{Reduction Behavior}

$\mathrm{H}_{2}$-TPR profiles of all catalysts are presented in Figure 2. The $\mathrm{KFe}$ catalysts presented two reduction peaks. The first, located in the range of $450-550^{\circ} \mathrm{C}$, corresponded to the reduction of iron oxides and the second peak, located above $650^{\circ} \mathrm{C}$, corresponded to the reduction of the reduced iron oxide phase. The addition of potassium slightly lowered the temperature of the reduction peaks when the potassium content was increased from $6 \mathrm{KFe}$ to $12 \mathrm{KFe}$. Further increase in the potassium content in the catalyst increased the temperature of the reduction peaks. Similar results were found for other iron-based catalysts (Bukur et al., 1999; Bukur and Sivaraj, 2002; Lin et al., 2003).

Compared to other iron-based catalysts supported on silica, the addition of potassium induced a pronounced effect in the TPR analysis mostly due to the interaction between the promoter and the support and the support and the metal. The $12 \mathrm{KFe}$ catalyst presented a slight reduction in the reduction temperature, probably due to a less pronounced interaction between the metal and the support (Lin et al., 2003). Total reduction of all catalysts was observed below $800^{\circ} \mathrm{C}$.

Pure iron oxide catalysts tend to show the first reduction peak around $480^{\circ} \mathrm{C}$ and the second peak around $650^{\circ} \mathrm{C}$. The addition of copper to the iron-based catalyst shifts the first and second peaks to lower values. Copper has a marked effect on the reduction of $\mathrm{Fe}_{2} \mathrm{O}_{3}$ to $\mathrm{Fe}_{3} \mathrm{O}_{4}$ (first peak). Hayakawa et al. (2006) have studied the effect of copper on iron-based catalysts. Catalysts with a $100 \mathrm{Fe}: 2 \mathrm{Cu}$ molar ratio lowered the first peak from $480^{\circ} \mathrm{C}$ to $323^{\circ} \mathrm{C}$, and the second peak from $650^{\circ} \mathrm{C}$ to $565^{\circ} \mathrm{C}$. Our results show that the addition of potassium increases the reduction temperature of $\mathrm{FeCu}$ catalysts to values similar than those shown by pure iron oxide catalysts.

Table 2: BET surface area, pore volume and average pore diameter of the catalysts.

\begin{tabular}{|l|c|c|c|c|}
\hline Catalyst & $\begin{array}{c}\text { BET } \\
\mathbf{s u r f a c e ~ a r e a ~} \\
{\left[\mathbf{m}^{\mathbf{2} / \mathbf{g}]}\right.}\end{array}$ & $\begin{array}{c}\text { Pore } \\
\text { volume } \\
{\left[\mathbf{c m}^{\mathbf{3}} / \mathbf{g}\right]}\end{array}$ & $\begin{array}{c}\text { Average } \\
\text { pore diameter } \\
{[\mathbf{n m}]}\end{array}$ & Reference \\
\hline Support & 286 & 0.93 & 26 & This work \\
$6 \mathrm{KFe}$ & 144 & 0.47 & 26 & This work \\
$12 \mathrm{KFe}$ & 138 & 0.47 & 26 & This work \\
$18 \mathrm{KFe}$ & 99 & 0.38 & 26 & This work \\
\hline Unsupported 3KFe & 55 & 0.33 & - & Hayakawa et al., 2006 \\
9KFe & 100 & - & - & Bukur and Sivaraj, 2002 \\
\hline
\end{tabular}




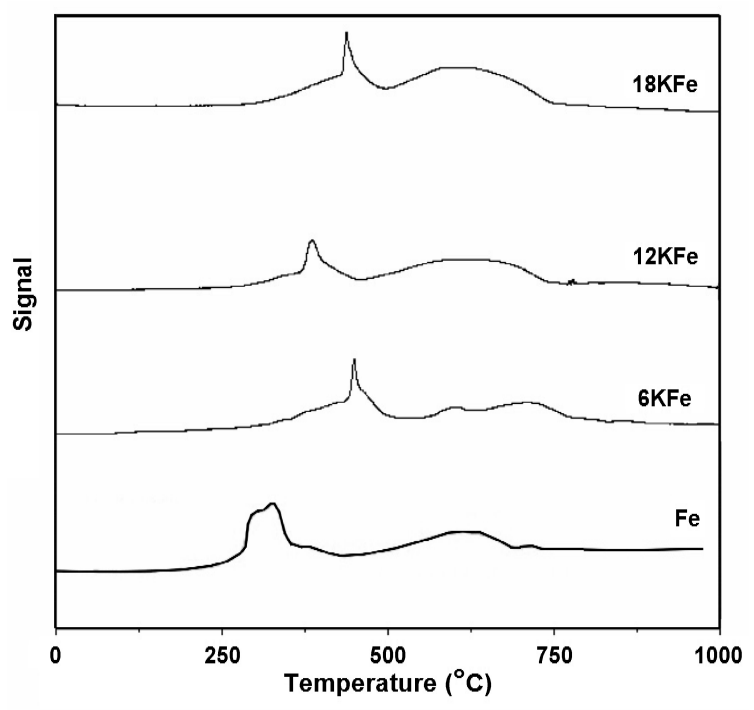

Figure 2: $\mathrm{H}_{2}$-TPR profiles of the catalysts with different potassium levels.

Figure 3 shows the effect of potassium on the curves of weight loss vs. temperature in a $\mathrm{H}_{2} / \mathrm{Ar}$ atmosphere. The two reductions observed in the TG pattern for all catalysts represent the reduction steps of $\alpha-\mathrm{Fe}_{2} \mathrm{O}_{3}$ to $\mathrm{Fe}_{3} \mathrm{O}_{4}$ and $\mathrm{Fe}_{3} \mathrm{O}_{4}$ to $\alpha$-Fe, respectively. The first loss of mass observed in Figure 3 (below $300^{\circ} \mathrm{C}$ ) corresponds to desorption of water, evaporation of solvents and oxidation of residues and non-incorporated nitrates. The loss of mass observed from 300 to $460^{\circ} \mathrm{C}$ corresponds to the reduction step of $\alpha-\mathrm{Fe}_{2} \mathrm{O}_{3}$ to $\mathrm{Fe}_{3} \mathrm{O}_{4}$ (Zhang et al., 2006). The loss of mass regarding the reduction step of $\mathrm{Fe}_{3} \mathrm{O}_{4}$ to $\alpha$-Fe was observed within the range of 550 to $700^{\circ} \mathrm{C}$.

The net weight loss at the same temperature point decreased with the increase of potassium levels, indicating that the reduction steps of $\alpha-\mathrm{Fe}_{2} \mathrm{O}_{3}$ to
$\mathrm{Fe}_{3} \mathrm{O}_{4}$ and of $\mathrm{Fe}_{3} \mathrm{O}_{4}$ to $\alpha-\mathrm{Fe}$ of the catalyst were retarded by the addition of potassium.

This decrease may be the result of an interaction between potassium oxide, copper oxide and iron oxide. A strong interaction of potassium oxide with iron oxide may suppress the adsorption of hydrogen on the catalyst surface and impede the reduction of iron oxide adjacent to the potassium promoter (Lund and Dumesic, 1982; Rankin and Bartholomew, 1986). The increase in $\alpha-\mathrm{Fe}_{2} \mathrm{O}_{3}$ crystallite size decreased the surface area for contact with the reductant $\mathrm{H}_{2}$ and may have contributed to the reduction phenomenon observed in the TG analysis. To explain better the TG analysis results, further studies should be carried out to understand fully the interaction between copper, potassium and iron.

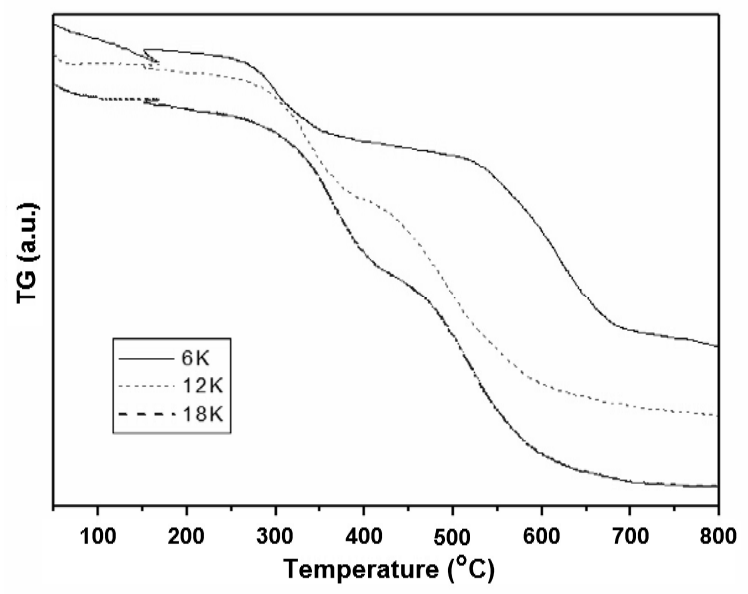

Figure 3: Thermal gravimetric (TG) curves for the catalysts with different potassium levels. 
DTG analyses are presented in Figure 4. Integration of the DTG profiles shows that the mass loss of the first reduction step $\left(\alpha-\mathrm{Fe}_{2} \mathrm{O}_{3}\right.$ to $\left.\mathrm{Fe}_{3} \mathrm{O}_{4}\right)$ increases from $36 \%$ of the total mass loss (Fe and $6 \mathrm{KFe}$ catalyst) to $38 \%$ of the total mass loss (18KFe catalyst). The inverse trend was observed in the second reduction step $\left(\mathrm{Fe}_{3} \mathrm{O}_{4}\right.$ to $\left.\alpha-\mathrm{Fe}\right)$, where the mass loss reduced from $64 \%$ of the total mass loss (Fe catalyst) to $56 \%$ of the total mass loss $(18 \mathrm{KFe}$ catalyst). Water desorption ranged from 6 to $7 \%$ of the total mass loss in all catalyst studied herein.

\section{SEM Analysis}

Figure 5 shows SEM micrographs of the catalysts. Figure 5a shows that the support is amorphous and does not present a well-defined structure. After impregnation with $\mathrm{Fe}, \mathrm{K}$ and $\mathrm{Cu}$, globular structures were formed over the support. The size of the globular structures increased with the incorporation of potassium, especially upon going from the $6 \mathrm{KFe}$ to the $12 \mathrm{KFe}$ catalyst.

The globular structures shown in Figure 5 were formed by an increase in the Fe crystallite size. This increase has been suggested by Dry and Oosthuizen (1968) and is related to the incorporation of strong bases like $\mathrm{K}$, which consequently decreases the surface area of the $\mathrm{Fe}$ catalyst.

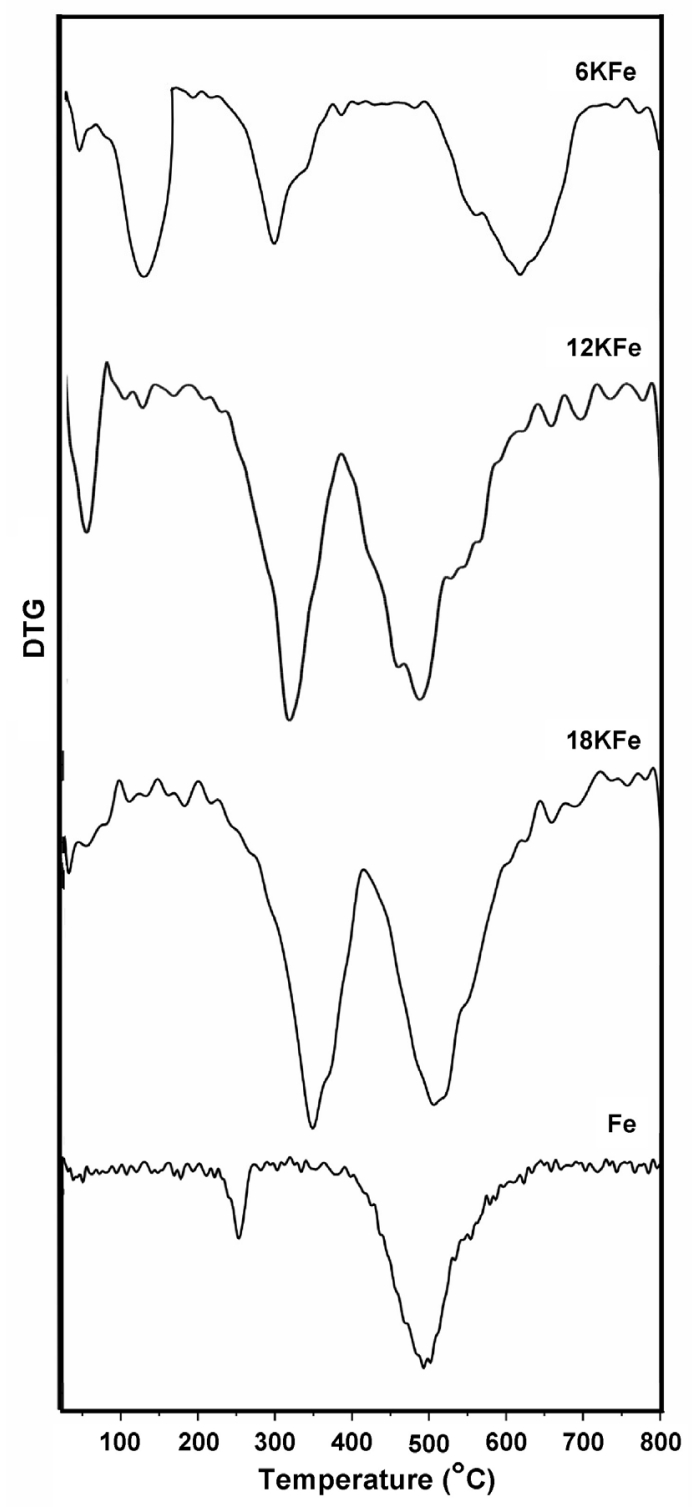

Figure 4: Differential thermal gravimetric (DTG) curves for the catalysts with different potassium levels. 

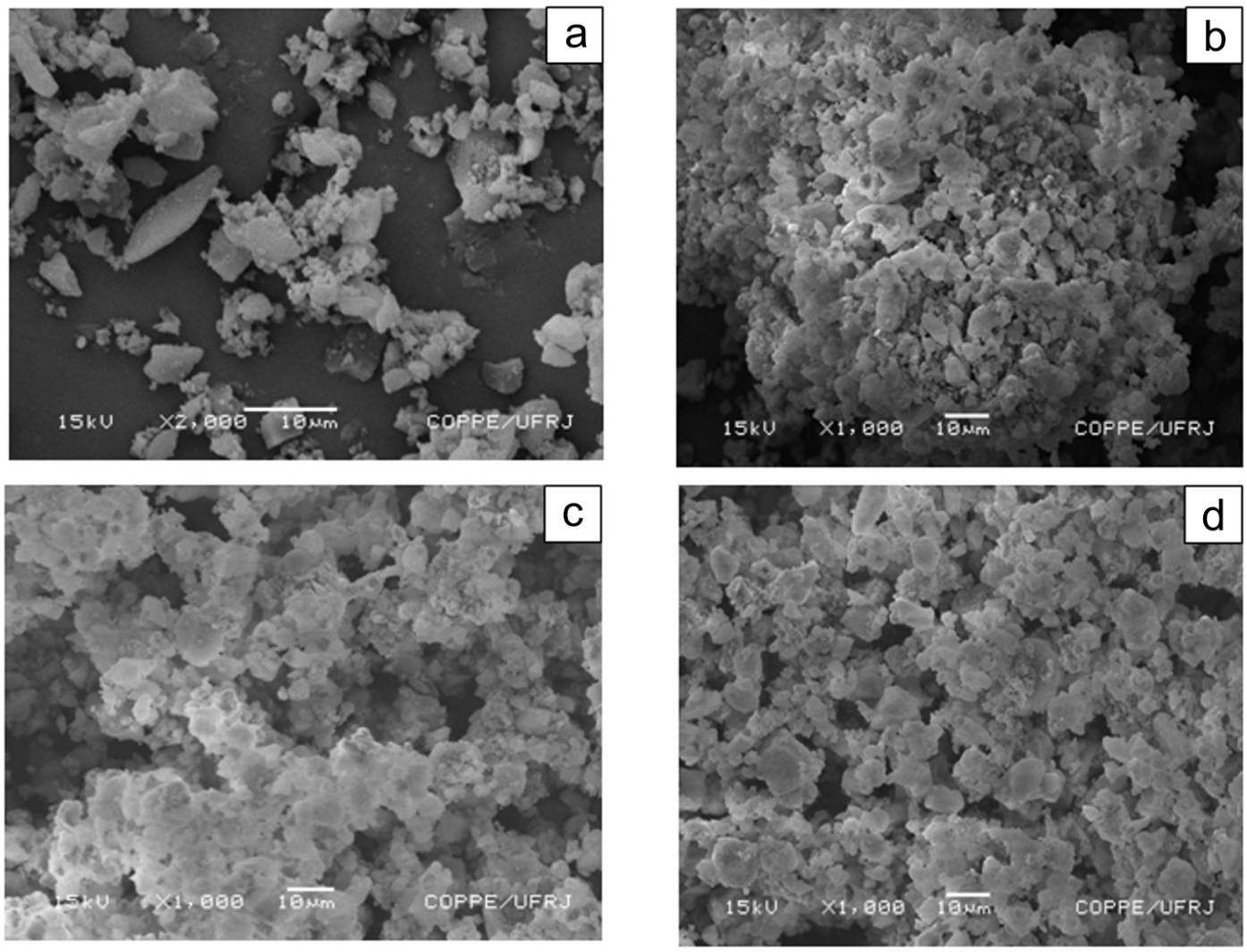

Figure 5: SEM analysis of the catalysts with different potassium levels. (a) support; (b) 6KFe; (c) $12 \mathrm{KFe}$; (d) $18 \mathrm{KFe}$.

\section{EDXS Analysis}

The elemental distributions for the cross-sections of the selected catalyst particles obtained from EDXS analysis are presented in Figure 6. The EDXS image of potassium showed a good distribution of the promoter over the support. The catalysts with high potassium content $(12 \mathrm{KFe}$ and $18 \mathrm{KFe})$ showed some regions where the promoter concentration was slightly higher.
Results presented by Sudsakorn et al. (2001) showed that potassium was found in a higher concentration in the outer region of the cross-section of particles, which was probably caused by the high potassium content in their catalyst $(4.2 \mathrm{wt} . \%)$. Higher concentration of potassium in the outer region of the catalyst was not observed in the catalyst prepared in this work, which may be related to the application of the incipient wetness method instead of a precipitation method.
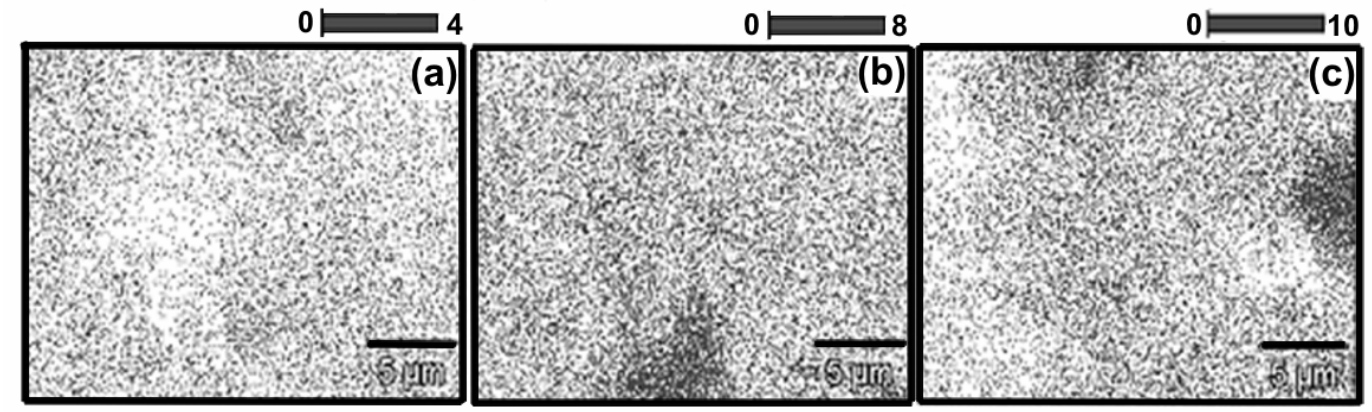

Figure 6: EDXS analysis of the catalysts with different potassium levels. (a) 6KFe; (b) $12 \mathrm{KFe}$; (c) $18 \mathrm{KFe}$. Images refer to potassium distribution only. 


\section{Catalyst Activity}

The conversion of $\mathrm{CO}$ into hydrocarbons ranged from 4 to $56 \%$ and depended highly on the operating conditions (Table 3). The conversion of syngas tended to increase with increasing pressure and increasing temperature. The conversion was slightly lower than the results reported by Bukur and Sivaraj (2002), who observed an average conversion of $60 \%$ with a $9 \mathrm{KFe}$ catalyst. The conversion was lower than the conversion observed by Luo and Davis (2003) $(73 \%)$ for a $1.5 \mathrm{KFe}$ precipitated iron-based catalyst.

The effect of the potassium content of the catalyst on the product distribution was complex. The increase in potassium content decreased the mass fraction of $\mathrm{C}_{1}$ and $\mathrm{C}_{2}$, especially at lower temperature and pressure. The shift toward higher hydrocarbons was more evident for the $18 \mathrm{KFe}$ catalyst, where the amount of $\mathrm{C}_{5+}$ was higher than $52 \%$ when the reactor operated at $240^{\circ} \mathrm{C}$ and 30 atm. The results shown in Table 3 show that a higher yield of heavier hydrocarbons was accompanied by a lower conversion of syngas. This feature may be explained by the occupation of the active sites. The formation of methane and other light gases is faster and may lead to higher total conversion of $\mathrm{CO}$, while the formation of higher hydrocarbons is slower, which may lead to lower total conversion of syngas.

The amount of heavy hydrocarbons (C20+) increased with pressure at low potassium content (6KFe), whereas the amount of heavy hydrocarbons decreased slightly with increasing pressure at high potassium content $(18 \mathrm{KFe})$. The catalyst $12 \mathrm{KFe}$ showed a slight increase in heavy hydrocarbons with pressure. The average carbon number was 28.4 for the $6 \mathrm{KFe}$ catalyst, 28.2 for the $12 \mathrm{KFe}$ catalyst and 28.8 for the $18 \mathrm{KFe}$ catalyst, differences that are not statistically significant. A statistical difference was observed only at low pressure. The average carbon number for the $6 \mathrm{KFe}$ catalyst and for the $12 \mathrm{KFe}$ catalyst was 26.3. The average carbon number for the $18 \mathrm{KFe}$ catalyst increased to 29.4 , showing that a high potassium to iron molar ratio increased the degree of polymerization of carbon monoxide at low pressure. Under this condition, the main hydrocarbon cut is shifted from diesel toward waxy products.

At low potassium contents, the concentration of adsorbed $\mathrm{H}$ atoms is greater and chain termination via hydrogenation is favored, which results in shorter chain hydrocarbons. On the other hand, dissociative $\mathrm{CO}$ adsorption is significantly enhanced as the potassium content increases, resulting in a higher concentration of $\mathrm{CH}_{2} \bullet$ species while the adsorption of $\mathrm{H}_{2}$ is more hindered (Lohitharn and Goodwin, 2008).

Results presented by Lohitharn and Goodwin (2008) showed a lower activity of catalysts with high potassium content (above 9KFe molar ratio), while catalysts below a $4 \mathrm{KFe}$ molar ratio presented similar activity in producing hydrocarbons. The lower activity reported by Lohitharn and Goodwin (2008) may be related to the mode of production of the catalyst (precipitation), which may be more susceptible to potassium addition than catalysts produced by the incipient wetness method.

Although the increase of potassium content in the catalyst increases the mass fraction of higher hydrocarbons, it also has a significant negative impact on conversion. The productivity of $\mathrm{C} 5+$ of the $6 \mathrm{KFe}$ catalyst and of the $12 \mathrm{KFe}$ catalyst is approximately 2.5 times higher than the productivity observed for the $18 \mathrm{KFe}$ catalyst. Thus, the production of higher hydrocarbons at the expense of lower conversion is not worthwhile from an industrial point of view. For industrial application, there is a limit to the amount of potassium promoter that should be added to the catalyst.

Table 3: CO conversion and hydrocarbon mass fractions for supported iron-based catalysts with different amounts of potassium after 8 hours on-stream.

\begin{tabular}{|c|c|c|c|c|c|c|c|}
\hline Run & $\begin{array}{c}\text { Temp. } \\
{\left[{ }^{\circ} \mathrm{C}\right]}\end{array}$ & $\begin{array}{c}\text { Pressure } \\
\text { [atm] }\end{array}$ & Catalyst & $\begin{array}{c}\text { Conversion } \\
{[\%]}\end{array}$ & $\mathrm{C}_{1}-\mathrm{C}_{2}$ & $\mathrm{C}_{3}-\mathrm{C}_{4}$ & $\mathrm{C}_{5+}$ \\
\hline 1 & 240 & 20 & $\mathrm{Fe}$ & 9 & 75.4 & 5.7 & 18.9 \\
\hline 2 & 240 & 30 & $\mathrm{Fe}$ & 21 & 51.7 & 9.4 & 38.9 \\
\hline 3 & 270 & 20 & $\mathrm{Fe}$ & 27 & 89.2 & 0.8 & 10.0 \\
\hline 4 & 270 & 30 & $\mathrm{Fe}$ & 56 & 93.1 & 0.8 & 6.1 \\
\hline 5 & 240 & 20 & $6 \mathrm{KFe}$ & 6 & 64.2 & 10.9 & 24.9 \\
\hline 6 & 240 & 30 & $6 \mathrm{KFe}$ & 55 & 84.5 & 5.4 & 10.1 \\
\hline 7 & 270 & 20 & $6 \mathrm{KFe}$ & 52 & 92.3 & 4.6 & 3.1 \\
\hline 8 & 270 & 30 & $6 \mathrm{KFe}$ & 54 & 87.6 & 5.0 & 7.4 \\
\hline 9 & 240 & 20 & $12 \mathrm{KFe}$ & 30 & 53.9 & 8.4 & 37.7 \\
\hline 10 & 270 & 30 & $12 \mathrm{KFe}$ & 55 & 82.7 & 6.6 & 10.7 \\
\hline 11 & 240 & 20 & $18 \mathrm{KFe}$ & 10 & 6.0 & 71.6 & 22.4 \\
\hline 12 & 240 & 30 & $18 \mathrm{KFe}$ & 4 & 16.1 & 31.5 & 52.4 \\
\hline 13 & 270 & 20 & $18 \mathrm{KFe}$ & 5 & 34.2 & 24.3 & 41.5 \\
\hline 14 & 270 & 30 & $18 \mathrm{KFe}$ & 53 & 69.2 & 19.8 & 11.0 \\
\hline
\end{tabular}




\section{CONCLUSIONS}

Incorporation of potassium promoter to an ironbased catalyst was found to have a significant influence on the adsorption and reduction behavior, as well as catalytic performance during Fischer-Tropsch synthesis. The changes in the catalytic performance can be primarily attributed to the effects of the potassium promoter on $\mathrm{H}_{2}$ adsorption, which further significantly affects the FTS performance of the catalysts.

The factors that most influenced the increase in the production of heavy hydrocarbons were the pressure and the potassium content of the catalyst. High pressures increased the average carbon number, while at low pressures the increase in the average carbon number was related to the increasing potassium to iron molar ratio of the catalyst.

\section{ACKNOWLEDGMENT}

The authors acknowledge financial and scholarship support from the Brazilian research funding institutions CNPq and CAPES.

\section{REFERENCES}

Bai, L., Xiang, H. W., Li, Y. W., Han, Y. Z. and Zhong, B., Slurry phase Fischer-Tropsch synthesis over manganese-promoted iron ultrafine particle catalyst. Fuel, 81, 1577 (2002).

Bartholomew, C. H. and Bowman, R. M., Sulfur poisoning of cobalt and iron Fischer-Tropsch catalyst. Appl. Catal., 15, 59 (1985).

Botes, F. G. and Böhringer, W., The addition of HZSM-5 to the Fischer-Tropsch process for improved gasoline production. Appl. Catal. A, 267, 217 (2004).

Bukur, D. B. and Sivaraj, C., Supported iron catalysts for slurry phase Fischer-Tropsch synthesis. Appl. Catal. A, 231, 201 (2002).

Bukur, D. B., Lang, X. S. and Ding, Y. J., Pretreatment effect studies with a precipitated iron Fischer-Tropsch catalyst in a slurry reactor. Appl. Catal. A, 186, 255 (1999).

Bukur, D. B., Mukesh, D. and Patel, S. A., Promoter effects on precipitated iron catalysts for FischerTropsch synthesis. Ind. Eng. Chem. Res., 29, 194 (1990).

Davis, B. H., Fischer-Tropsch synthesis: Comparison of performances of iron and cobalt catalysts. Ind. Eng. Chem. Res., 46, 8938 (2007).
Dry, M. E. and Oosthuizen, G. J., The correlation between catalyst surface basicity and hydrocarbon selectivity in the Fischer-Tropsch synthesis. J. Catal., 11, 18 (1968).

Dun, J. W., Gulari, E. and Ng, K. Y. S., Fischertropsch synthesis on charcoal-supported molybdenum: The effect of preparation conditions and potassium promotion on activity and selectivity. Appl. Catal., 15, 247 (1985).

Farias, F. E. M., Sales, F. G. and Fernandes, F. A. N., Effect of operating conditions and potassium content on Fischer-Tropsch liquid products produced by potassium-promoted iron catalysts. J. Nat. Gas. Chem., 17, 175 (2008).

Hayakawa, H., Tanaka, H. and Fujimoto, K., Studies on precipitated iron catalysts for Fischer-Tropsch synthesis. Appl. Catal. A, 310, 24 (2006).

Jin, Y. and Datye, A. K., Phase transformations in iron Fischer-Tropsch catalysts during temperatureprogrammed reduction. J. Catal., 196, 8 (2000).

Li, T., Yang, Y., Zhang, C., An, X., Wan, H., Tao, Z., Xiang, H., Li, Y., Yi, F. and Xu, B., Effect of manganese on an iron-based Fischer-Tropsch synthesis catalyst prepared from ferrous sulfate. Fuel, 86, 921 (2007).

Lin, H. Y., Chen, Y. W. and Li, C., The mechanism of reduction of iron oxide by hydrogen. Thermochim. Acta, 400, 61 (2003).

Lohitharn, N. and Goodwin Jr., J. G., Effect of K promotion of $\mathrm{Fe}$ and FeMn Fischer-Tropsch synthesis catalysts: Analysis at the site level using SSITKA. J. Catal., 260, 7 (2008).

Lou, M. and Davis, B. H., Fischer-Tropsch synthesis: Group II alkali-earth metal promoted catalysts. Appl. Cat. A, 246, 171 (2003).

Lund, C. R. F. and Dumesic, J. A., Strong oxideoxide interactions in silica-supported magnetite catalysts. 2. The core/shell nature of the interaction. J. Phys. Chem., 86, 130 (1982).

Maiti, G. C., Malessa, R. and Baerns, M., Iron/manganese oxide catalysts for fischertropsch synthesis. Part I: structural and textural changes by calcination, reduction and synthesis. Appl. Catal., 5, 151 (1983).

Maiti, G. C., Malessa, R., Löchner, U., Papp, H. and Baerns, M., Iron/manganese oxide catalysts for Fischer-Tropsch synthesis. Part II: Crystal phase composition, activity and selectivity. Appl. Catal., 16, 215 (1985).

Martínez, A. and López, C., The influence of ZSM-5 zeolite composition and crystal size on the in situ conversion of Fischer-Tropsch products over hybrid catalysts. Appl. Catal. A, 294, 251 (2005). 
Miller, D. G. and Moskovits, M., A study of the effects of potassium addition to supported iron catalysts in the Fischer-Tropsch reaction. J. Phys. Chem., 92, 6081 (1988).

Pour, A. N., Zare, M. and Zamani, Y., Studies on product distribution of alkali promoted iron catalyst in Fischer-Tropsch synthesis. J. Nat. Gas. Chem., 19, 31 (2010).

Qin, S., Zhang, C., Xu, J., Wu, B., Xiang, H. and Li, Y., Effect of Mo addition on precipitated $\mathrm{Fe}$ catalysts for Fischer-Tropsch synthesis. J. Mol. Catal. A, 304, 128 (2009).

Rankin, J. L. and Bartholomew, C. H., Effects of potassium and calcination pretreatment on the adsorption and chemical/physical properties of Fe SiO2. J. Catal., 100, 533 (1986).

Sudsakorn, K., Goodwin Jr., J. G., Jothimurugesan, K. and Adeyiga, A. A., Preparation of attritionresistant spray-dried Fe Fischer-Tropsch catalysts using precipitated $\mathrm{SiO} 2$. Ind. Eng. Chem. Res., 40, 4778 (2001).
Tao, Z., Yang, Y., Zhang, C., Li, T., Ding, M., Xiang, H. and Li, Y., Study of Manganese Promoter on a Precipitated Iron-Based Catalyst for Fischer-Tropsch Synthesis. J. Nat. Gas. Chem., 16, 278 (2007).

Wan, H., Wu, B., Zhang, C., Xiang, H. and Li, Y., Promotional effects of $\mathrm{Cu}$ and $\mathrm{K}$ on precipitated iron-based catalysts for Fischer-Tropsch synthesis. J. Mol. Catal. A., 283, 33 (2008).

Wu, B., Bai, L., Xiang, H., Li, Y. W., Zhang, Z. E. and Zhong, B., An active iron catalyst containing sulfur for Fischer-Tropsch synthesis. Fuel, 83, 205 (2004).

Yang, Y., Xiang, H. W., Xu, Y. Y., Bai, L. and Li, Y. W., Effect of potassium promoter on precipitated iron-manganese catalyst for Fischer-Tropsch synthesis. Appl. Catal. A, 266, 181 (2004).

Zhang, C. H., Wan, H. J., Yang, Y., Xiang, H. W. and Li, Y. W., Study on the iron-silica interaction of a co-precipitated $\mathrm{Fe} / \mathrm{SiO} 2$ Fischer-Tropsch synthesis catalyst. Catal. Comm., 7, 733 (2006). 